\title{
COVID-19 - A Pandemic \& a Policy Driver to Healthcare System in India
}

\author{
IJCRR \\ Section: Healthcare \\ Sci. Journal Impact \\ Factor: 6.1 (2018) \\ ICV: 90.90 (2018) \\ Scopus'
}

\section{Narahari KV ${ }^{1}$, Sowjanya M$^{2}$, Vishwanath BA $^{1}$, Saravanan $\mathrm{J}^{2}$}

\author{
'Aditya Bangalore lnstitute for Pharmacy Education and Research, Yelahanka, Bangalore, Karnataka, India; ${ }^{2}$ PES University, Faculty of \\ Pharmaceutical Sciences, Hanumanthanagar, Bangalore, Karnataka, India
}

\section{ABSTRACT}

The present article provides a brief review on sources of health disparities, pandemic risks and burdens, various impact factors (such as political disruptions, state-centre imbalance, lack of trained health professionals) hindering policy-making on pandemics. Further, factors responsible for outbreak mismanagement with strategies for effective preparedness is focused. It also highlights the age-old colonial law, so-called the backbone of Indian healthcare policy in strategizing healthcare emergencies. The gaps in the present policy indicate an immediate requirement for an overarching law that governs public health care. The review also envisages the safety and security measures taken by the Indian government against COVID-19, prioritising health over the economy. Finally, flagship changes required in national healthcare policy to prepare the country to fight against any upcoming pandemic outbreaks are suggested.

Key Words: Healthcare policy, Indian government, Pandemic risks, Preparedness

\section{BACKGROUND}

Pandemics are large-scale outbreaks of infectious diseases that can greatly increase morbidity and mortality over a wide geographic area and cause significant socio-economic and political disruption. Due to global travel, integration, modernisation, exploitation of environment including land over the past century seems to have led to increased occurrence of pandemics. The policy-makers have mainly focussed on identification of emerging disease outbreaks and ways to control them than expanding on investment to build preparedness and providing quality healthcare. The first National Health Policy (NHP) of India was formulated in $1983^{5,2}$ by Bhore Commission which gave direction to an Indian public health service during Independence ${ }^{2}$, also influenced by the Alma Ata Declaration ${ }^{20}$ of Health focusing on primary health care to all by the year 2000. Further in 2002, the NHP was revised by focussing on public health through decentralization $^{6}$. In 2017, the rules were further revised focusing to improve health status through concerted policy action in all sectors and quality expansion of preventive, promotive, curative, palliative, and rehabilitative services. ${ }^{7}$ All these policy frameworks suffer to give attention for implementation of surveillance, preparedness, vaccination, and public health response during pandemic outbreaks.
The frequency of the emergence of pandemic diseases has increased multi-fold. The international community has made progress towards preparing and mitigating the impacts of pandemics. Various pandemic outbursts such as SARS 2003, Influenza 2009, MERS 2012, West Africa Ebola 2014, etc. have led many countries to intensify pandemic planning and management. Global health care bodies (WHO) have framed many pandemic regulations and policies, for detection, response, and reporting during outbreaks. Despite these improvements, significant gaps and challenges exist in global pandemic preparedness.

In a pandemic event - geographical factors, policy lapses, social determinants, and other factors can result in health disparities that are enumerated in Table I. ${ }^{17}$

\section{DISCUSSION}

Pathogens from livestock, domestic, and wildlife reservoirs constitute SPARK risk. Travel, trade, and migration are responsible for the spread of spark risks that constitute SPREAD risk. The combination of these two risks in various geographical regions results in pandemic outbursts especially in Low and Middle-Income Countries (LMICs) with weak health care systems ${ }^{10,13}$.

\section{Corresponding Author:}

Narahari KV, Aditya Bangalore Institute of Pharmacy Education and Research, \#12, Behind Annapurneshwari temple, Yelahanka, Bangalore - 560064, Karnataka, India; Mob: +91-9535808182; Email: kvn2121@gmail.com

ISSN: 2231-2196 (Print)

ISSN: 0975-5241 (Online)

Received: 26.05 .2020

Revised: 20.06 .2020

Accepted: 07.07 .2020

Published: 22.07 .2020 
The COVID-19 pandemic has revealed lacunae in the healthcare system, education, and training of Pharmacy Professionals (PPs) and other healthcare professionals for Emergency Preparedness and Response (EP\&R) in India ${ }^{1}$. A systematic review on the population needs is a prerequisite to enable effective emergency responses through the EP\&R framework.

A systematic review on the population needs is a prerequisite to developing an EP\&R framework to enable effective emergency responses.

Lack of historical data and uncertainty regarding bioterrorism-related events could hypothetically lead to a pandemic. Novel methods such as probabilistic modelling and exceedance probability curves can be used to assess and estimate pandemic risks and burdens.

Pandemics can cause significant, widespread morbidity and mortality as well as socio-economic and political disruptions ${ }^{18}$. Pandemics can cause economic damage through multiple channels. For instance, the total healthcare cost to handle ZIKA Virus ${ }^{3}$ scenario was approx. 28.9 billion dollars.

The Pandemic Influenza virus continued to circulate as seasonal influenza virus. From January 2013 to $27^{\text {th }}$ October $2013^{8}$ there had been 5200 laboratory confirmed cases with 684 deaths. The states which reported sporadic outbreaks with a large number of cases and deaths are Gujarat, Maharashtra, Haryana, Karnataka, Punjab, Madhya Pradesh, Rajasthan, Tamil Nadu, Uttar Pradesh, Andhra Pradesh, and Chandigarh.

The COVID-19 outbreak, which has now spread to six continents, will stall out. But the outbreak should be a wakeup call (not as previously ignored with SARS in 2003 and flu pandemic of 2009) about infectious threats that we face together and that exploit vulnerabilities associated with income inequality, health disparities, and our slowness to recognize the threats.

As demonstrated in Figure $\mathbf{I}^{10}$, well-prepared countries have effective public institutions, strong economies, and adequate investment in the health sector. They have built specific competencies critical in detecting and managing disease outbreaks, including surveillance, mass vaccination, and risk communications. Poorly prepared countries may suffer from political instability, weak public administration, inadequate resources for public health, and gaps in fundamental outbreak detection and response systems ${ }^{10}$

The main objective of the National Health Policy $2017^{7}$ is to inform, clarify, strengthen and prioritise the role of the Government in shaping health systems in all its dimensionsinvestments in health, organisation of healthcare services, prevention of diseases and promotion of good health through cross-sectorial actions, access to technologies, developing human resources, encouraging medical pluralism, building knowledge base, developing better financial protection strategies, strengthening regulation and health assurance.

The Indian National Health Policy 2017 is being supported by United Nations in achieving the goals of Sustainable Development (UNU-IIGH, 2018) in order to attain the highest possible level of health and well-being to all at all ages through preventive and promotive health care. Though SDGs have been given pivotal importance in NHP 2017 but pandemic outbreak management still struggles to find a better place. Even as the government ramps up efforts to tackle the COVID-19 pandemic, the primary law, it resorts to, is the 123-year old The Epidemic Diseases Act, 1897, that governs healthcare emergencies in India. The colonial-era law, enacted to fight the bubonic plague in the erstwhile Mumbai, comprises of four sections spread over just three pages. Experts point out one of the primary issues facing administrators dealing with the pandemic situation is the federal structure of Indian democracy. The power granted to the Centre under this Act is very limited and provides the ultimate discretion of the state government to take a step by framing appropriate regulation.

The fiscal profligacy and mismanagement by most state governments and imbalances in the sharing of resources and constitutional responsibilities, have made them more dependent on the central government for financial resources. This has disrupted the balance of powers and responsibilities between the centre and the states ${ }^{12}$. It has not only affected the implementation of health programmes, but also governance and security, which all point to the urgency for a more state-specific approach to health policy.

Moreover, not all states have framed regulations to control the pandemic. While the government also declared the disease as a 'notified disaster' under the Disaster Management Act, the fact remains that India does not have dedicated legislation for a pandemic situation. An overarching law governing public healthcare is a glaring gap in India's fight against the COVID-19 pandemic.

The four major gaps plaguing the Act include the rights of healthcare personnel, travel restrictions, privacy rights, and investments needed to meet the healthcare challenge. Many changes need to be implemented in domestic laws though India is a signatory to WHO's International Health Regulations (IHR).

For example, a complete ban on commercial flights may not align with Article 43 of the IHR ${ }^{8}$, which calls for proportionality of such bans to potential risk. Likewise, the privacy of a patient's medical information should be balanced with public disclosure based on needs. Experts believe no such provision to maintain this balance is available under the current laws. An overarching law could also include provisions for an emergency fund to deal with such situations ${ }^{16}$. 
A study conducted in Ujjain, India, revealed that Informal HealthCare Professionals (IHCPs) are predominant prescribers in rural India ${ }^{11}$. It indicated that the IHCPs prescribe antibiotics more commonly than other medications for common illnesses in both children and adults. For example, fluoroquinolones, and cephalosporins $\left(3^{\text {rd }} \text { generation }\right)^{17}$ Such ill prescriptions shall result in the emergence of most virulent ABRs forms.

Implementation of more frequent in-service training of public health medical personnel - medical officers as well as paramedics would help not only to update them but also equip in delivering challenging assignments ${ }^{9}$.

\section{Fighting pandemics around the world ${ }^{16}$}

Australia: An overarching law called the National Health Security Act and Agreement has been put in place.

United States: Under the Public Health and Service Act, the US Department of Health and Human Services has laid down specific guidelines to assist states during health emergencies and prevent the spread of communicable diseases.

EU: EU Decision 1082/13 is the key legal instrument for threats to health, which endorses compliance with WHO's IHR.

Spain: All private hospitals have been nationalized in the wake of the pandemic.

India: The Epidemic Diseases Act, 1897, governs health care emergencies.

We are slow to recognize threats, so we panic, but we don't prepare. We tend to overreact to problems that are facing us right now but under react to long-term threats that build slowly. We're willing to take heroic measures to treat a heart attack, but slower to prevent heart attacks from happening. Take the current run on face masks. They won't protect you from your neighbour's coronavirus, but a shortage of masks to protect health care professionals who need to treat sick people means we could all suffer.

Experts have been warning of the dangers of disease outbreaks for decades, prescribed a set of steps to help deal with the current outbreak. For instance, Bill Gates called for a data surveillance system that would instantly give relevant organisations the information they need about potential outbreaks and prevent future pandemics. He donated \$100 million $^{24}$ and suggested that the government should spend billions of dollars to build manufacturing plants for vaccines that would normally provide routine vaccinations (drug companies now handle this, for-profit) but could be refitted during a pandemic.

Current vaccine research, development, and production timelines are not conducive to quick responses to pandemic threats. For example, despite biomedical advances, most influenza vaccines are produced through vaccine platforms that rely on the availability of embryonated chicken eggs and can take several months to produce. Vaccines that are in development may take decades to become available for human use. For example, Ebola vaccines were in development for more than a decade, with the first vaccine approved for clinical use only in 2015.

\section{Steps Taken During Covid-19 in India}

Our Honourable Prime Minister Narendra Modi has shown leadership in mobilizing the heads of government of the SAARC and G20 nations to share reliable information, best practices, and supports each other in fighting this pandemic.

The Indian government has so far followed a step-bystep model and been on the front foot with an early screening at airports from mid-January onwards, initiating travel restrictions and in collaboration with states, applying restrictions on events, and on places of social gathering including restaurants, theatres, and gyms. Such a response ensured that there was no panic among the citizens and avoided inconvenience to the extent possible.

The government has taken proactive measures for national lockdown and expansion of focused testing, to identify hot spots for isolation, quarantining, and care.

Also significantly increasing health expenditures to strengthen the health system response and promoting $R \& D$ is appreciable. Indian government has taken necessary steps by depositing cash on a monthly basis for the foreseeable future through Jan Dhan scheme.

Introduced the Aarogya Setu app ${ }^{23}$ for the coronavirus tracking, contact tracing, and to connect with people to health services. The scope of Ayushman Bharat, India's flagship insurance/assurance scheme launched with the vision of universal healthcare and leaving no one behind, should be expanded to include the 40 percent 'missing middle' who are neither covered by private insurance nor by the government so that any COVID-19-related expenses are covered by the government.

The Indian government has also evacuated more than 1400 of its citizens from high-risk countries such as China, Japan, Iran, and Italy. By Operation Samudra Setu ${ }^{21}$, the Indian Navy is set to rescue stranded Indians from the Maldives due to Coronavirus induced lockdown and brought to Kochi (then quarantined for 14days). Through the Vande Bharat Mission ${ }^{14}$, India sent 64 flights and three Navy ships to repatriate Indians stranded abroad due to the coronavirus pandemic.

Atma-Nirbhar Bharat Abhiyann ${ }^{22}$, a comprehensive special economic package of 20 lakh crore rupees (equivalent to 10 percent of India's GDP) for labourers, farmers, honest 
taxpayers, MSMEs, and cottage industry emphasizing 4Ls land, labour, liquidity, and laws is a masterstroke in boosting the economy.

\section{CONCLUSION}

The world is 'a playground' for viruses like the novel coronavirus that causes Covid-19, infectious disease. We must realise that in our crowded world of 7.8 billion people, a combination of altered human behaviours, environmental changes, and inadequate global public health mechanisms now easily turn obscure animal viruses into existential human threats.'

The Covid-19 pandemic has rapidly disrupted our everyday life. Cities and states are on lockdown in a desperate effort to flatten the curve. Policy changes matter, and not just because they make us feel good about doing the right thing. They matter because health is a human right and deeply interdependent.

- In order to flatten the curve, the health of people irrespective of caste, colour, creed, gender, and economic status need to be protected. Without protecting these populations, our health care system will collapse leaving all of us at risk.

- Adequate monetary management for pandemic preparedness is preferred than taking heroic measures after the pandemic outbreak.

- The central and the state governments should work in unison irrespective of the political establishment in power to manage the pandemic situation.

- The most effective strategies for pandemic preparedness consist of investing to strengthen core public health infrastructure including water and sanitation systems; increasing situational awareness and rapidly extinguishing sparks that could lead to pandemics.

- The policy should prioritise the development of R\&D wing for a quick and effective response to virulent pathogens, a plug-and-play vaccine that can immediately be deployed against any new pathogen and latest treatments and vaccines being tested at a speed that would have until now been unfathomable.

- The government must also continue to ensure coverage of COVID-19 related expenses with consistent and credible communication about public health guidance and to allay any fears and panic among the populace till the end of the pandemic.

- To avoid imbalances in the sharing of resources and responsibilities between state and centre a legal gazette providing monitoring power to the centre with state-specific approach to health policy.

- All private companies should mandatorily include pandemic management fund as part of CSR (Corporate Social Responsibility).
- A better working environment should be provided for healthcare professionals in un-served areas. The ill-effects of a pandemic may fade but a permanent change in the healthcare policy shall protect the system at large. Our system has the potential to be forever changed - for the better.

- As we fight this pandemic together - governments, businesses, civil society, and citizens require great resilience and adaptability. With an approach that includes the whole society, together we can and will fight this coronavirus pandemic. 'PREPARE - DON'T PANIC IS THE MANTRA'.

Acknowledgement: Our sincere and heartfelt thanks to all the authors and Government of India whose articles are cited and included in the manuscript

\section{Financial Support: No funding}

Conflict of Interest: The authors declare that there is no conflict of interest associated with this article.

\section{REFERENCES}

1. Aruru Meghana, Yerramilli Aparna, Sekar M. Chandra, and Sharma Sanjeev. Emergency preparedness and response (EP\&R) by pharmacy professionals in India: Lessons from the COVID-19 pandemic and the way forward. Res Social Adm Pharm 2020; doi: 10.1016/j.sapharm.2020.04.028. [Epub ahead of print]

2. Bhore J, Amesur RA, Banerjee AC. Report of the Health Survey and Development Committee. Vol. I. Government of India1946; New Delhi.

3. Bruno Abarca, Ueslei Marcelino, Ueslei Marcelino, Pallavi Yagnik. A Socio-economic Impact Assessment of the Zika Virus in Latin America and the Caribbean: with a focus on Brazil, Colombia and Suriname2017. The United Nations Development Programme (UNDP) in partnership with the International Federation of Red Cross and Red Crescent Societies (IFRC).

4. Government of India 1996. The Constitution of India. New Delhi: Government of India.

5. National Health Policy 1983. New Delhi Ministry of Health and Family Welfare, Govt of India 1983. http://www.nhp.gov. in/sites/default/files/pdf/nhp_1983.pdf, accessed on 3 May,2020

6. National Health Policy 2002. Ministry of Health and Family Welfare, Govt of India 2002. http://www.nhp.gov.in/sites/ default/files/pdf/NationaL_Health_Pollicy.pdf , accessed on 4 May,2020

7. National Health Policy 2017. Ministry of Health and Family Welfare, Govt of India 2017. https://www.nhp.gov.in/nhpfiles/ national_health_policy_2017.pdf, accessed on 4 May, 2020

8. Annual Report 2013-2014, MOHFW, Government of India., Department of Health and Family Welfare,https://nhm.gov.in/ images/pdf/media/publication/Annual_Report-Mohfw.pdf, accessed on 7 May,2020

9. M Chokshi, B Patil, R Khanna, S B Neogi, J Sharma, V K Paul, and S Zodpey. Health systems in India. J Perinatol 2016; 36(Suppl 3): S9-S12. doi: 10.1038/jp.2016.184.

10. Nita Madhav, Ben Oppenheim, Mark Gallivan, Prime Mulembakani, Edward Rubin, and Nathan Wolfe. Pandemics: Risks, Impacts, and Mitigation. Washington (DC): The International Bank for Reconstruction and Development / The World Bank2017. 
11. Alexander Fleming,Penicillin, Nobel lecture 1945;https://www. nobelprize.org/uploads/2018/06/fleming-lecture.pdf , accessed on 11 May 2020

12. Peters DH, Rao KS, Fryatt R. Lumping and splitting: the health policy agenda in India. Health Policy Plan 2003; 18(3): 249260. Oxford University Press.

13. Management's Discussion \& Analysis and Financial Statements.The World Bank 2017;http://pubdocs.worldbank.org/ en/476501524663465554/IBRD-Jun-17.pdf, accessed on 17 June 2020

14. Covid-19 India evacuation Highlights: Expats disappointed as flight from Doha to Kerala capital is cancelled 2020; https://indianexpress.com/article/india/india-evacuation-live-updates-usuk-uae-saudi-arabia-kerala-delhi-mumbai-6401197/,accessed on 11 May 2020

15. India's National Health Policy 2017 and 2030 Agenda for Sustainable Development. United Nationals University. International Institute for Global Health. https://iigh.unu.edu/publications/ blog/indias-national-health-policy-2017-and-2030-agenda-forsustainable-development.html, accessed on 14 May 2020

16. To fight a pandemic like Covid-19, India needs overarching healthcare laws 2020; https://www.business-standard.com/article/current-affairs/to-fight-a-pandemic-like-covid-19-indianeeds-overarching-healthcare-laws-120032201137_1.html, accessed on 22 March 2020

17. Shweta Khare, Manju Purohit, Megha Sharma, Ashok J. Tamhankar, Cecilia Stalsby Lundborg, Vishal Diwan, Ashish Pathak et al. Antibiotic Prescribing by Informal Healthcare Providers for Common Illnesses: A Repeated Cross-Sectional Study in
Rural India. Antibiotics (Basel) 2019; 8(3); 139. doi: 10.3390/ antibiotics8030139.

18. Supriya Kumar, Sandra C Quinn. Existing health inequalities in India: informing preparedness planning for an influenza pandemic. In Health Policy and Planning. Oxford University 2012; 27: 516-526.

19. WHO. Pre-Antibiotic Era Looming Large-The World is Almost out of Time 2014. http://www.searo.who.int/mediacentre/ features/2014/rd-statement-amr2014/en/, accessed on 10 May 2020

20. WHO and UNICEF. Geneva: World Health Organization. Primary Health Care: Report on the International Conference on Primary Health Care, Alma Ata 1978; USSR: 6-12.

21. Operation Samudra Setu 2020. https://blog.nextias.com/operation-samudra-setu.,accessed on 06 May 2020

22. At $10 \%$ of GDP, Modi's Atma-nirbar Bharat Abhiyan ranks among biggest in the world 2020. https://economictimes.indiatimes.com/news/economy/finance/at-10-of-gdp-modis-atmanirbhar-bharat-abhiyan-ranks-among-biggest-in-world/articleshow/75716267.cms.,accessed on 13 May 2020

23. Aarogya Setu:Who can access your data, and when? 2020., https://indianexpress.com/article/explained/coronavirus-aarogya-setu-who-all-can-access-your-data-and-when-6407175/, accessed on 14 May 2020

24. The coronavirus exposes our health care system's weaknesses. We can be stronger 2020. https://www.statnews.com/2020/03/02/ the-coronavirus-exposes-our-health-care-systems-weaknesseswe-can-be-stronger/, accessed on 02 March 2020

\section{Table I: Sources of health disparities}

(Shweta Khare, et al., Antibiotic Prescribing by Informal Healthcare Providers for Common Illnesses: A Repeated Cross-Sectional Study in Rural India. Antibiotics, 2019)

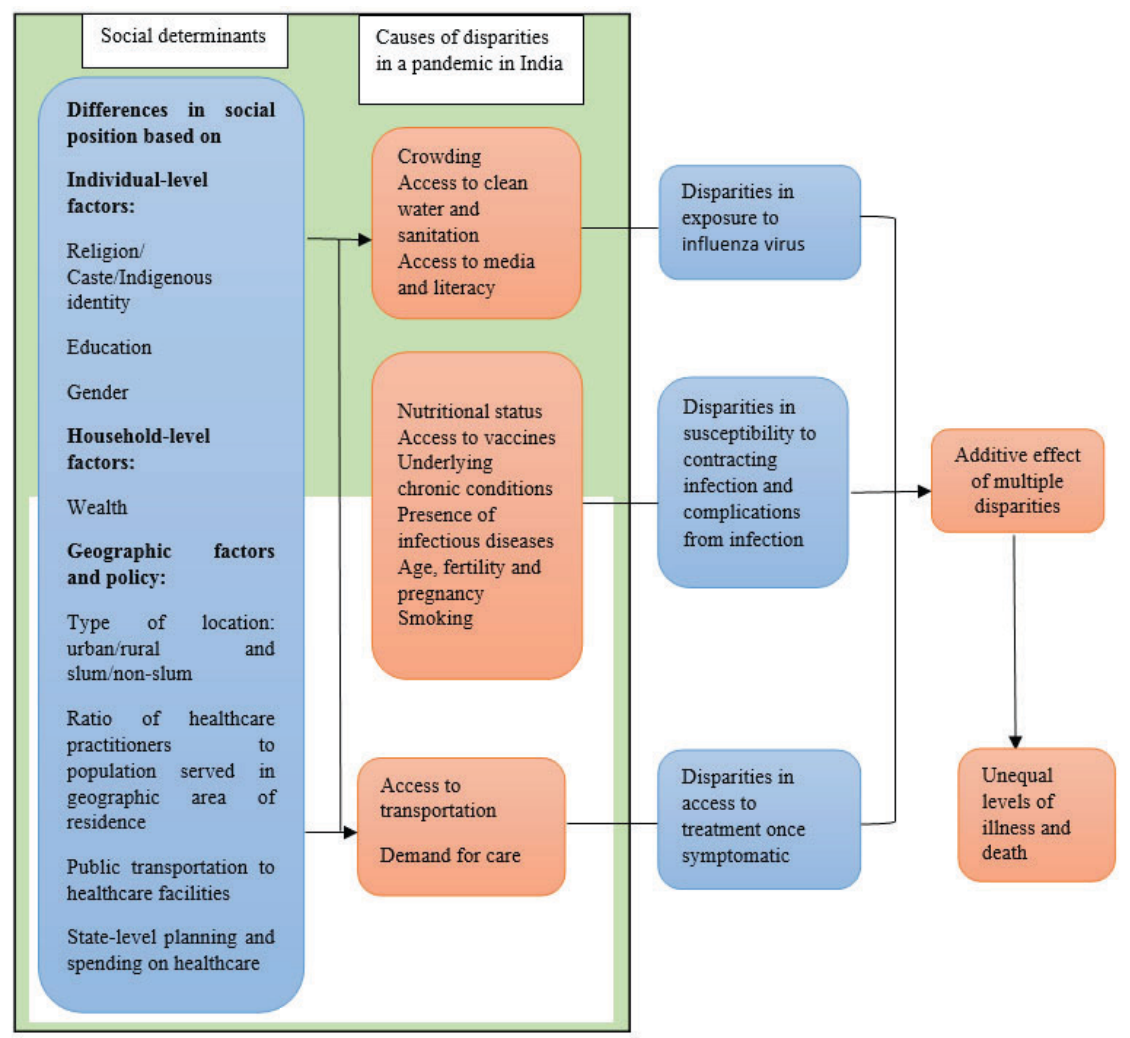




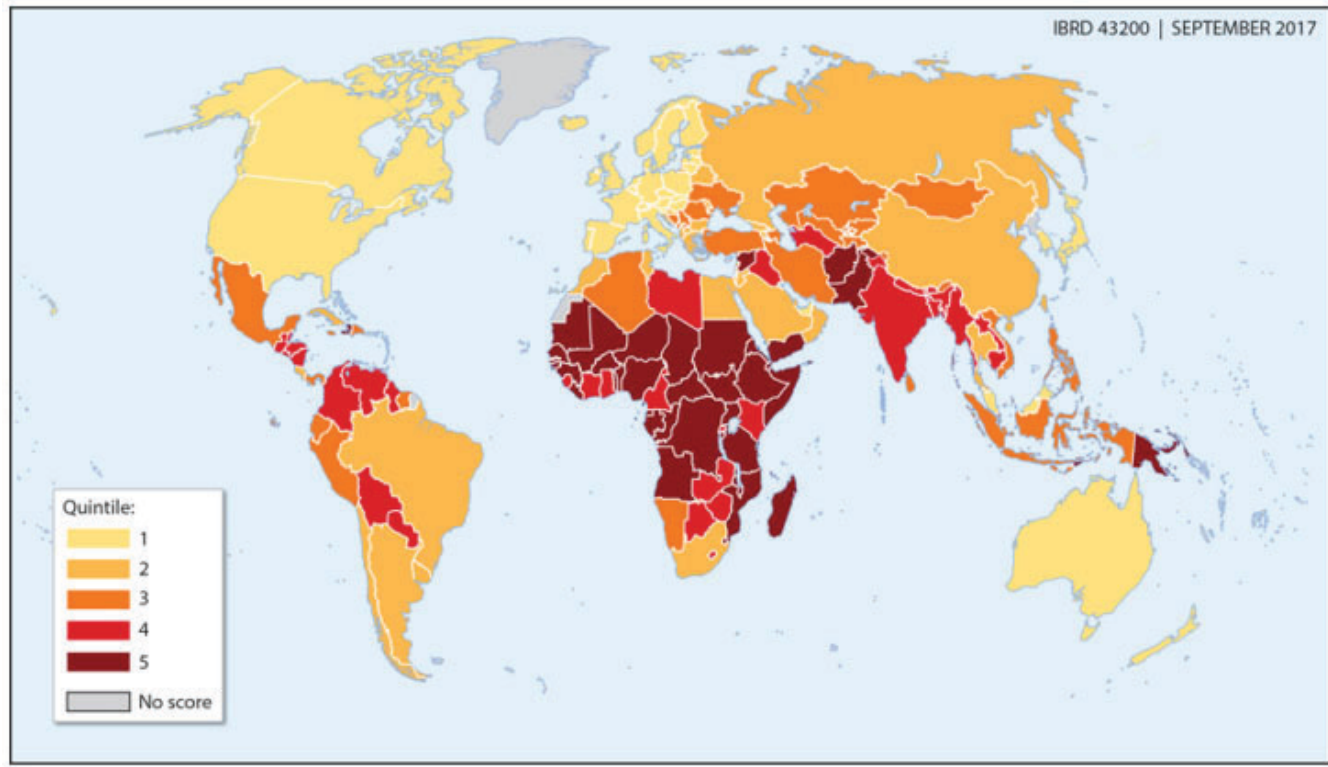

Figure I: Global Distribution of Epidemic Preparedness, 2017 - Countries are grouped into quintiles of epidemic preparedness (1 = most prepared, 5 = least prepared)

(Nita Madhav et al., Pandemics: Risks, Impacts, and Mitigation. Washington (DC): The International Bank for Reconstruction and Development / The World Bank. 2017) 